\title{
PERSISTENCIA DE Salmonella Typhimurium EN NOPAL VERDURA (Opuntia ficus-indica)
}

\author{
Salmonella Typhimurium PERSISTANCE IN PRICKLE PEAR (Opuntia ficus-indica)
}

\author{
Patricia Landa Salgado ${ }^{1}$, Ana María Hernández Anguiano ${ }^{1 \star}$, Mateo Vargas Hernández ${ }^{2}$, \\ Carlos A. Eslava Campos ${ }^{3}$, Cristóbal Chaidez Quíroz ${ }^{4}$ Jitu Patel ${ }^{5}$
}

\begin{abstract}
${ }^{1}$ Campus Montecillo, Colegio de Postgraduados. km 36.5 Carretera México-Texcoco. 56230, Montecillo, Texcoco, Edo. de México. ${ }^{2}$ Universidad Autónoma Chapingo. km 38.5 Carretera México-Texcoco. 56230, Texcoco, Edo. de México. ${ }^{3}$ Universidad Nacional Autónoma de México, Ciudad Universitaria. 04510, Coyoacán, Distrito Federal. ${ }^{4}$ Centro de Investigación en Alimentación y Desarrollo A. C. km 5.5 Carretera a El Dorado. 80129, Culiacán, Sinaloa . ${ }^{5}$ USDA-ARS, ANRI, Bldg. 201, Rm 10. 110300 Baltimore Ave., BARC-East. Beltsville, MD 20705: 595 (95) 20200 Ext. 1610, 1606.
\end{abstract}

•Autor para correspondencia (ahernandez@colpos.mx)

\section{RESUMEN}

En este trabajo se evaluó la capacidad de $S$. entérica serovar Typhimurium ( $S$. Typhimurium) para persistir en cladodios de nopal verdura (Opuntia ficus-indica) y en suelo, así como determinar si las plantas responden a inoculaciones con la bacteria, y comparar dicha respuesta entre diferentes cladodios (cladodios madre, secundarios in planta, y secundarios cortados). S. Typhimurium persistió en suelo y tejido de nopal hasta por $14 \mathrm{~d}$. La capacidad de la bacteria para persistir en el tejido dependió del tipo y la condición fisiológica del cladodio. En cladodio secundario in planta la bacteria persistió $9 \mathrm{~d}$; en cladodio madre in planta y cladodio secundario cortado persistió $14 \mathrm{~d}$, con diferencias $(\mathrm{P} \leq \mathbf{0 . 0 5})$ en la población bacteriana entre tipos y condiciones fisiológicas del cladodio. En tejido, $S$. Typhimurium indujo lesiones oscuras en el sitio de infiltración en todos los cladodios, lesiones que fueron más intensas en cladodios secundarios in planta a las $48 \mathrm{~h}$, además de síntomas de deshidratación y desprendimiento de tejido. En ausencia de la bacteria no se registraron alteraciones en el tejido. Los síntomas observados indican que $S$. Typhimurium tiene capacidad de activar señales e inducir una respuesta de defensa en nopal verdura.

Palabras clave: Opuntia ficus-indica, Salmonella, persistencia.

\section{SUMMARY}

In this study, $S$. enterica serovar Typhimurium ( $S$. Typhimurium) ability of to persist in prickle pear plants (Opuntia ficus-indica) was evaluated persistence in the soil, plant response to bacterial contamination, as well as comparison of the response among several cladodes (mother cladodes, secondary cladodes in planta, and cut cladodes). was evaluated $S$. Typhimurium persisted in soil and in plant tissue for up to $14 \mathrm{~d}$. Its persistence in the cladode on the type and physiological condition of the cladode. In secondary in plant cladodes the bacterium persisted for $9 \mathrm{~d}$, while in the mother in plant cladodes and cut secondary cladodes persisted for $14 \mathrm{~d}$, with differences $(P \leq 0.05)$ in the bacterial population between cladode types and physiological conditions. In the tissue, $S$. Typhimurium induced dark lesions at the infiltration site in all cladodes, lesions were more intense in plant secondary cladodes at $48 \mathrm{~h}$ and showed symptoms of tissue dehydration and detachment. In the absence of the bacteria there were no changes in the tissue. The observed symptoms indicate that $S$. Typhimurium is capable of activating signals and induce a defense response in prickle pear plants.

Index words: Opuntia ficus-indica, Salmonella, persistence.

\section{INTRODUCCIÓN}

El nopal (Opuntia ficus-indica) es una de las principales especies hortofrutícolas producidas en México. Sus tallos o cladodios (nopales verdura o "nopalitos") se comercializan y se consumen en fresco, generalmente por sus propiedades alimenticias y medicinales. El nopal verdura ocupa el primer lugar entre las plantas utilizadas para el tratamiento de diabetes (Saucedo-Tamayo et al., 2006). Sin embargo, recientemente se advirtió la presencia de Salmonella en cladodios frescos obtenidos de plantaciones de nopal donde es común la aplicación de abono orgánico fresco (HernándezAnguiano et al., 2009).

Salmonella es una bacteria enteropatógena cuyo hábitat natural es el tracto intestinal de mamíferos (domésticos y silvestres), reptiles, aves e insectos. Diferentes serotipos de Salmonella han mostrado capacidad de persistir, es decir, de mantenerse por tiempo prolongado fuera de su hábitat natural y adaptarse a condiciones adversas del ambiente. Por ejemplo, los serotipos Typhimurium y Montevideo de S. entérica persistieron en tomate (Solanum lycopersicon) por 9 y 49 d, respectivamente (Guo et al., 2002; Guo et al., 2001); y por $231 \mathrm{~d}$ en perejil (Petroselinum hortense) (Islam et al., 2004). En aguas de río y potable, el serotipo Typhimurium persistió por 45 y 152 d (Santo Domingo et al., 2000; Guan y Holley, 2003). Este mismo serotipo persistió por $7 \mathrm{~d}$ en suelo seco y por $63 \mathrm{~d}$ en suelo húmedo (Zibilske y Weaver, 1978).

Salmonella tiene capacidad de proliferar en la superficie de tejidos vegetales (Solomon et al., 2002) y también de colonizar tejidos internos de los mismos (Guo et al., 2001), como en semillas, hojas y frutos. Muchos de estos productos consumibles han sido involucrados en brotes de salmonelosis (Doyle y Erickson, 2008). Guo et al. (2001) identificaron células de $S$. enterica en la pulpa de frutos de tomate, frutos que fueron colectados de plantas inoculadas en etapa de floración, por inyección de tallo y cepillado de flores, con los serotipos Poona, Michigan, Enteritidis, Montevideo y Hartford.

También Warriner et al. (2003) observaron células de un mutante bioluminiscente del serotipo Montevideo, en los espacios intercelulares de la epidermis del hipocotilo de plántulas de frijol mungo (Vigna radiata), a las $24 \mathrm{~h}$ de 
iniciada la germinación de semillas contaminadas con la bacteria; además recuperaron células viables de la bacteria, del fluido apoplástico y de extractos de germinados previamente desinfestados con hipoclorito de sodio. Franz et al. (2007) aislaron células del serotipo Typhimurium transformadas con el plásmido de la proteína verde fluorescente, del tejido interno de plántulas de lechuga (Lactuca sativa), crecidas en suelo y en un sistema hidropónico, ambos contaminados con la bacteria. Lo anterior sugiere que Salmonella puede tener a las plantas como hospedantes alternos.

Algunos genotipos vegetales responden específicamente a Salmonella (Klerks et al., 2007 a, b), lo que indica que las interacciones entre plantas y patógenos de humanos no son accidentales, sino programadas genéticamente (Holden et al., 2009). Al respecto, Barak et al. (2005) mencionaron que Salmonella requiere de genes de virulencia, como el gen invA, para colonizar los tejidos de las plantas.

Por su parte, Iniguez et al. (2005) y Schikora et al. (2012) indicaron que las plantas activan mecanismos de defensa en respuesta a enteropatógenos como Salmonella, con efecto en las poblaciones de estos patógenos; según estos autores, la activación del sistema de defensa se debe esencialmente a la presencia del sistema de secreción tipo tres (TTSS, por sus siglas en inglés) y de compuestos extracelulares como la flagelina, en las cepas de Salmonella, compuestos que son reconocidos por receptores de las plantas involucrados en las respuestas de defensa dependientes e independientes del ácido salicílico y de la activación de proteínas relacionadas con el desarrollo de la enfermedad. En contraste, los mutantes del serotipo Typhimurium carentes de estos componentes pudieron colonizar con éxito a tejidos internos de las plantas (Iniguez et al., 2005).

Se ha señalado que las plantas infectadas por Salmonella son asintomáticas, pero estudios recientes han mostrado el desarrollo de síntomas como marchitez, pérdida de biomasa y amarillamiento (Schikora et al., 2008), así como inducción de una reacción hipersensible en el tejido vegetal (Shirron y Yaron, 2011). En observaciones preliminares de cladodios de nopal verdura infiltrados in planta con Salmonella se registraron cambios en la coloración del tejido interno durante las primeras horas después de la infiltración; por la rapidez y características de la respuesta del tejido, así como por la delimitación de la lesión al sitio de inoculación, se consideró que podría tratarse de una respuesta de defensa en la planta de nopal a Salmonella.

Por lo anterior, los objetivos de este trabajo fueron: 1) Evaluar la capacidad de S. enterica serovar Typhimurium ( $S$. Typhimurium) de persistir en nopal verdura y en suelo plantado con nopal, cuando la planta o la rizosfera del suelo son inoculados con Salmonella; 2) Registrar la respuesta del tejido de nopal a la presencia de S. Typhimurium; y 3) Comparar dicha respuesta entre cladodios in planta y cladodios cortados.

\section{MATERIALES Y MÉTODOS}

\section{Material vegetal y cepa bacteriana}

Se utilizaron plantas de nopal de la var. 'Milpa Alta', de nueve meses, crecidas en macetas de plástico con una mezcla de suelo-vermicomposta $(3.5: 1.5 \mathrm{~kg})$ de textura franco arenosa (arena $62 \%$, limo $31.3 \%$ y arcilla $6.7 \%$ ), regadas por gravedad con agua de pozo (dos riegos por semana) y mantenidas en invernadero para la producción de cladodios. Previo a su utilización, se hizo un análisis bacteriológico de muestras del agua de riego, con resultado negativo a la presencia de organismos coliformes, termotolerantes y $E$. coli presuntiva (NMX-AA-102-SCFI-2006).

La cepa utilizada para inocular fue el serovar Typhimurium ATCC23564, resistente a kanamicina (SigmaAldrich $\left.{ }^{\circledR}\right)\left(50 \mu \mathrm{g} \mathrm{mL}^{-1}\right)$ (S. Typhimurium), donada por el Centro de Investigación en Alimentación y Desarrollo, A. C. (Landa-Salgado et al., 2009), y almacenada en una solución de agua-glicerol (50:50) a $-20{ }^{\circ} \mathrm{C}$. Previo al establecimiento de los experimentos, la bacteria se reactivó en caldo soya tripticaseína (CST) más kanamicina $\left(\mathrm{CST}-\mathrm{Km}^{50}\right)$ a 37 ${ }^{\circ} \mathrm{C}$ por $48 \mathrm{~h}$, y se creció en agar soya tripticaseína más $\mathrm{Km}^{50}$ $\left(\mathrm{AST}-\mathrm{Km}^{50}\right.$ ). De las cajas con crecimiento bacteriano se preparó el inóculo en agua peptonada amortiguada (APA) $0.1 \%$, con pH de 7.0. El suelo y los cladodios (de 20 a 25 $\mathrm{cm}$ ) se inocularon durante las primeras $2 \mathrm{~h}$ después de haberse preparado el inóculo.

\section{Inoculación de suelo}

Un volumen de $300 \mathrm{~mL}$ de suspensión de $S$. Typhimurium con $8.4 \log _{10} / \mathrm{mL}$ de unidades formadoras de colonias (UFC) en APA $0.1 \%$, se infiltró en el suelo de una maceta con una planta de nopal, sin salpicar la planta. En total se inocularon 45 macetas con suspensión bacteriana, y como testigo se contó con 15 macetas a las que se les aplicó solo APA $0.1 \%$. Este experimento de inoculación se hizo dos veces.

\section{Inoculación de cladodios in planta y cladodios cortados}

Para determinar la capacidad de $S$. Typhimurium de persistir en los tejidos internos del nopal, un volumen de 300 $\mu \mathrm{L}$ de suspensión bacteriana con $7.4 \log _{10}$ UFC en APA 0.1 $\%$ se infiltró a través de la aguja metálica (30G x $13 \mathrm{~mm}$ ) de una jeringa de $1 \mathrm{~mL}$ (BD Ultra-Fine ${ }^{\circledR}$ ), en la parte superior del cladodio. In planta se inocularon 45 cladodios madre y 
45 cladodios secundarios, uno de cada uno por planta; más 15 cladodios secundarios cortados. Como testigos se usaron cinco cladodios madre y cinco secundarios in planta, y cinco cladodios cortados, todos ellos inyectados con APA $0.1 \%$ sin la bacteria. Este método de inoculación se repitió de nuevo con el mismo número de cladodios. Después de la inoculación los cladodios in planta se mantuvieron en invernadero, y los cortados en laboratorio. Durante $14 \mathrm{~d}$ se colectó cada 24 h un cladodio madre y uno secundario in planta, y uno cortado, para observar la aparición de síntomas y detectar cambios en la coloración en el tejido interno mediante cortes longitudinales en los cladodios.

\section{Persistencia de Salmonella en suelo y tejido de nopal}

Después de la inoculación, cada 24 h durante 15 d se colectaron muestras de suelo, de cladodios madre y secundarios in planta, de plantas elegidas al azar, así como de cladodios cortados.

Persistencia en suelo. Se analizaron muestras de suelo (25 g por maceta) de tres macetas inoculadas con $S$. Typhimurium y de una maceta testigo por día. Cada muestra se depositó en una bolsa Ziploc® estéril y se analizó inmediatamente de acuerdo con la norma NOM-114-SSA1-1994. Cada muestra de suelo se mezcló con $225 \mathrm{~mL}$ de APA 0.1 $\%$, con agitación por $30 \mathrm{~s}$. De la mezcla homogeneizada se tomó una alícuota de $2 \mathrm{~mL} ; 1 \mathrm{~mL}$ se transfirió a un tubo con $9 \mathrm{~mL}$ de APA $0.1 \%$ para hacer diluciones seriales, y de cada dilución se depositaron $100 \mu \mathrm{L}$ por duplicado en agar entérico Hektoen más $\mathrm{Km}^{50}\left(\mathrm{AEH}-\mathrm{Km}^{50}\right)$, y se incubaron a $37^{\circ} \mathrm{C}$ por $48 \mathrm{~h}$. El otro mililitro se usó para enriquecimiento en CST- $\mathrm{Km}^{50}$. De las suspensiones bacterianas obtenidas se tomaron muestras con un asa estéril y se estriaron en $\mathrm{AEH}-\mathrm{Km}^{50}$. El medio inoculado se incubó a $37^{\circ} \mathrm{C}$ por $48 \mathrm{~h}$.

Persistencia en tejido. Se colectaron tres cladodios madre y tres cladodios secundarios in planta; así como uno secundario cortado, por día, y cada cladodio se depositó sobre papel aluminio previamente esterilizado con luz UV (Lámpara PHILIPS® UV 30W/630 T8) por $15 \mathrm{~min}$, y se procesaron en las siguientes $2 \mathrm{~h}$ de acuerdo con la NOM114-SSA1-1994. Previo a la extracción, los cladodios se lavaron con agua corriente de la llave y se desinfestaron por separado con hipoclorito de sodio (Reasol ${ }^{\circledR}$ ) a $200 \mathrm{mg} \mathrm{L}^{-1}$ por $3 \mathrm{~min}$, se enjuagaron con agua destilada, se colocaron sobre papel aluminio y mantuvieron en una cámara de bioseguridad (ThermoForma ${ }^{\circledR}$, Class II Biological Safety Cabinet).

La extracción y estimación del número de células viables de $S$. Typhimurium se hizo con el protocolo de Madigan et al. (2001). Del área de inoculación de cada cladodio se cortó $1 \mathrm{~cm}^{2}$ de tejido con una navaja estéril, se depositó en $900 \mu \mathrm{L}$ de APA $0.1 \%$, y la mezcal se maceró en un molino (Seward $\AA$, Stomacher 400 circulator) por $1 \mathrm{~min}$ a $300 \mathrm{rpm}$. Del macerado se tomaron tres muestras de $100 \mu \mathrm{L}$ cada una; una para siembra directa en $\mathrm{AEH}-\mathrm{Km}^{50}$, otra para hacer diluciones seriales, y una más para enriquecimiento en CST$\mathrm{Km}^{50}$. De las suspensiones obtenidas se tomaron muestras con un asa estéril y se estriaron en $\mathrm{AEH}-\mathrm{Km}^{50}$, y luego los medios se incubaron a $37^{\circ} \mathrm{C}$ por $48 \mathrm{~h}$.

Se obtuvieron 12 cepas presuntivas de Salmonella aisladas en AEH-Km ${ }^{50}: 3$ de suelo, 5 de cladodios madre, 1 de cladodios secundarios in planta, y 3 de cladodios secundarios precortados. De cada cepa se extrajo ADN de células crecidas en tubos con $5 \mathrm{~mL}$ de CST- $\mathrm{Km}^{50}$ sin agitación, a $37^{\circ} \mathrm{C}$ por $24 \mathrm{~h}$; la extracción se hizo de acuerdo con Guo et al. (2000) para la amplificación del gen invA con los iniciadores Sal-3 y Sal-4, y con un paquete (PCR Master Mix, Promega $\left.{ }^{\circledR}\right)$ para la determinación de la reacción en cadena de la polimerasa (PCR, por sus siglas en inglés), como propusieron Rahn et al. (1992). Como testigo positivo se incluyó ADN de $S$. Typhimurium. La reacción se efectuó en un termociclador de gradiente (Techne $\AA$, TC-512) con el programa: desnaturalización inicial a $94{ }^{\circ} \mathrm{C}$ por $1 \mathrm{~min} ; 35$ ciclos, cada uno con: desnaturalización a $94^{\circ} \mathrm{C}$ por $1 \mathrm{~min}$, alineación de iniciadores a $50{ }^{\circ} \mathrm{C}$ por $1 \mathrm{~min}$, extensión de $\mathrm{ADN}$ a $72^{\circ} \mathrm{C}$ por $2 \mathrm{~min}$; y extensión final a $72^{\circ} \mathrm{C}$ por $5 \mathrm{~min}$. El producto de PCR esperado, una banda de $275 \mathrm{pb}$, se analizó por electroforesis en gel de agarosa $0.8 \%$ con bromuro de etidio $(1 \mu \mathrm{L})$ y se visualizó en un transiluminador (Gene

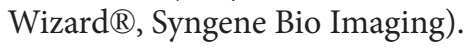

\section{Respuesta del tejido de nopal a Salmonella}

Para el seguimiento de la aparición de síntomas (daños) en los cladodios después de la inoculación, cada $24 \mathrm{~h}$ durante $7 \mathrm{~d}$ se colectaron tres cladodios madre y tres secundarios in planta y tres cladodios cortados, tanto de plantas inoculadas con $S$. Typhimurium como de plantas testigo no inoculadas. Inmediatamente después se realizaron cortes longitudinales en los cladodios y se registraron los cambios en coloración y consistencia del tejido interno inoculado. Para el análisis comparativo entre cladodios in planta y los cortados, se usó una escala porcentual donde: $0=$ sin oscurecimiento de tejido; 25 = oscurecimiento tenue de tejido; $50=$ oscurecimiento denso de tejido; $75=$ oscurecimiento $y$ deshidratación de tejido; y $100=$ oscurecimiento, deshidratación y desprendimiento de tejido (Figura 1).

\section{Análisis estadístico}

Los datos de poblaciones bacterianas obtenidos de ensayos se transformaron a $\log _{10} \mathrm{UFC} / \mathrm{g}$ de suelo o tejido. Los datos se sometieron a análisis de varianza con un diseño 


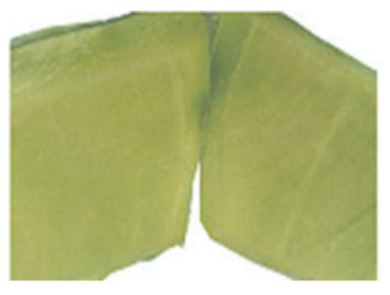

$0 \%$

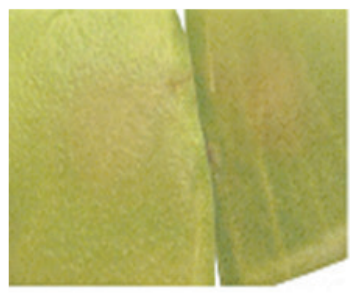

$25 \%$

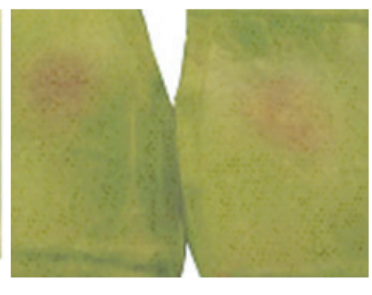

$50 \%$

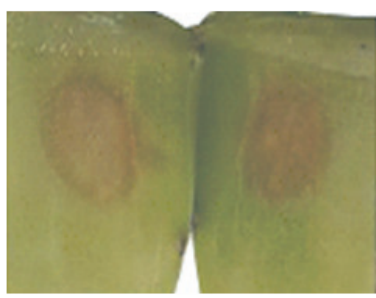

$75 \%$

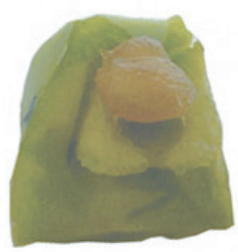

$100 \%$

Figura 1. Escala porcentual usada para comparar el grado de daño en cladodios inoculados con $S$. Typhimurium. Dónde: $0=$ sin oscurecimiento (testigo); $25=$ con oscurecimiento tenue; $50=$ con oscurecimiento denso; $75=$ con oscurecimiento tenue o denso y deshidratación de tejido; y 100 = con oscurecimiento denso, deshidratación y desprendimiento de tejido.

completamente al azar, y a una prueba de comparación múltiple de medias (Tukey, 0.05). La respuesta del tejido a Salmonella se sometió a análisis de correlación de Pearson entre el tiempo y el nivel de daño registrado en los cladodios.

\section{RESULTADOS Y DISCUSIÓN}

\section{Persistencia de Salmonella Typhimurium}

Persistencia en suelo. S. Typhimurium persistió por 14 d después de la inoculación (ddi) del suelo plantado con nopal. Después de este tiempo no se detectó la bacteria, aun en muestras sometidas a enriquecimiento en CST-Km ${ }^{50}$. En suelo, el decremento de la población bacteriana fue paulatino y constante, hasta alcanzar niveles de $1 \log _{10} \mathrm{UFC/g}$ o menos, después de 9 ddi (Cuadro 1). La capacidad de Salmonella de persistir en suelo es muy variable, con periodos desde 7 hasta 63 d (Natving et al., 2002; Ziblinske y Weaver, 1978). Diversos factores pueden afectar la persistencia de bacterias enteropatógenas en suelo. Por ejemplo, Vidovic et al. (2007) reportaron alta tasa de mortalidad de E. coli $\mathrm{O} 157: \mathrm{H7}$, a $22^{\circ} \mathrm{C}$ en suelo franco arenoso limoso con baja concentración de carbono (2\%) y presencia de microbiota nativa, en contraste con un suelo esterilizado y rico en carbono.

Persistencia en tejido. En cladodios madre in planta S. Typhimurium persistió por $14 \mathrm{~d}$, con decremento gradual y constante de la población, hasta alcanzar niveles de $1 \log _{10}$ UFC/g o menos, después de 9 ddi. En cladodios secundarios in planta, Salmonella persistió por $9 \mathrm{ddi}$, pero la población decreció rápidamente durante las primeras $24 \mathrm{~h}$ hasta alcanzar niveles de $1 \log _{10} \mathrm{UFC} / \mathrm{g}$ o menos, después de 5 ddi; a partir de los 10 ddi no se recuperó a la bacteria, ni en medios enriquecidos. En cladodios secundarios cortados la bacteria persistió en el tejido por $14 \mathrm{ddi}$; al inicio la población bacteriana registró un decremento durante los primeros $8 \mathrm{ddi}$, para luego mostrar un incremento paulatino de cerca de $2 \log _{10}$, resultado que contrasta con lo registrado en suelo y en cladodios in planta (Cuadro 1). En persistencia hubo diferencia significativa $(\alpha=0.05)$ entre los cladodios in planta y los cortados.

Los productos de amplificación por PCR de todas las muestras de las cepas presuntivas de Salmonella (de suelo $\mathrm{y}$ de cladodios in planta y cortados en $\mathrm{AEH}-\mathrm{Km}^{50}$ ), dieron bandas de 275 pb, similares al de la banda obtenida con el serotipo de $S$. Typhimurium.

Estos resultados muestran que $S$. Typhimurium tiene capacidad de persistir en tejido interno de plantas de nopal, aunque su duración depende del tipo de cladodio y de su condición fisiológica. En cladodio secundario la capacidad de persistir y de crecimiento fue limitada, posiblemente asociado con un cambio de color en este tipo de tejido, de verde a café. En contraste, en cladodio secundario cortado el incremento en la población puede estar relacionado con una respuesta tardía en procesos metabólicos como degradación de lípidos en membranas celulares, y por el deterioro postcosecha del tejido que expone nutrimentos esenciales para el desarrollo de Salmonella (Stintzing y Carle, 2005).

Según Pu et al. (2009), las hojas de espinaca (Portulaca oleracea) de tres a cinco semanas de edad fueron más susceptibles a la colonización por E. coli O157:H7, que las hojas de tres semanas. En contraste, Brandl y Amudson (2008) encontraron poblaciones similares de Salmonella en tejido joven de lechuga in planta y en lechuga cortada. Estas diferencias indican que la colonización por Salmonella puede estar relacionada con el tipo de planta y de tejido.

La capacidad de Salmonella de persistir y de colonizar tejidos vegetales internos es relevante para evaluar contaminación de frutas y hortalizas para consumo en fresco. Actualmente ningún proceso de lavado y desinfestación es $100 \%$ efectivo para remover o eliminar las células bacterianas que pudieran venir adheridas a la superficie de 
Cuadro 1. Días de persistencia de $S$. Typhimurium en suelo y cladodios de nopal.

\begin{tabular}{|c|c|c|c|c|}
\hline \multirow{3}{*}{ Días $^{\dagger}$} & \multicolumn{4}{|c|}{ Población bacteriana $\left(\log _{10}\right.$ de UFC/g) ${ }^{\dagger+,}$} \\
\hline & \multirow{2}{*}{ Suelo } & \multicolumn{2}{|c|}{ Cladodio in planta } & \multirow{2}{*}{$\begin{array}{c}\text { Cortado } \\
\text { Secundario }\end{array}$} \\
\hline & & Madre & Secundario & \\
\hline 1 & $4.7 \mathrm{a}$ & $5.6 \mathrm{a}$ & $2.3 \mathrm{ab}$ & $3.6 \mathrm{a}$ \\
\hline 2 & $4.3 \mathrm{ab}$ & $4.0 \mathrm{~b}$ & $3.0 \mathrm{a}$ & $3.1 \mathrm{abc}$ \\
\hline 3 & $3.7 \mathrm{bc}$ & $4.0 \mathrm{~b}$ & $1.4 \mathrm{cde}$ & $3.3 \mathrm{~b}$ \\
\hline 4 & 2.8 cde & $3.3 \mathrm{bc}$ & $2.2 \mathrm{abc}$ & $2.6 \mathrm{bcd}$ \\
\hline 5 & $2.7 \mathrm{cde}$ & $3.7 \mathrm{bc}$ & $2.1 \mathrm{bcd}$ & $2.0 \mathrm{~cd}$ \\
\hline 6 & $2.2 \mathrm{def}$ & $4.0 \mathrm{~b}$ & $0.6 \mathrm{efg}$ & $2.0 \mathrm{~cd}$ \\
\hline 7 & $2.0 \mathrm{efg}$ & $2.0 \mathrm{e}$ & $1.1 \mathrm{def}$ & $2.2 \mathrm{bcd}$ \\
\hline 8 & $2.1 \mathrm{efg}$ & $2.8 \mathrm{de}$ & $0.7 \mathrm{efg}$ & $1.8 \mathrm{~d}$ \\
\hline 9 & $2.0 \mathrm{efg}$ & $3.1 \mathrm{~cd}$ & $0.1 \mathrm{~h}$ & $1.8 \mathrm{~cd}$ \\
\hline 10 & $1.9 \mathrm{fgh}$ & $0.3 \mathrm{~g}$ & $0.0 \mathrm{~h}$ & $2.1 \mathrm{~cd}$ \\
\hline 11 & $1.6 \mathrm{ghi}$ & $0.0 \mathrm{~g}$ & $0.0 \mathrm{~h}$ & $2.5 \mathrm{bcd}$ \\
\hline 12 & $1.1 \mathrm{hij}$ & $0.0 \mathrm{~g}$ & $0.0 \mathrm{~h}$ & $2.4 \mathrm{bcd}$ \\
\hline 13 & $0.5 \mathrm{jk}$ & $1.1 \mathrm{f}$ & $0.0 \mathrm{~h}$ & $3.7 \mathrm{a}$ \\
\hline 14 & $0.5 \mathrm{jk}$ & $0.3 \mathrm{~g}$ & $0.0 \mathrm{~h}$ & $3.7 \mathrm{a}$ \\
\hline 15 & 0.01 & nd & nd & nd \\
\hline
\end{tabular}

${ }^{\dagger}$ Después de la inoculación con 8.4 y $7.4 \log _{10} \mathrm{UFC} / \mathrm{mL}$, para suelo y cladodios, respectivamente. ${ }^{\dagger \dagger}$ Promedio de dos ensayos, cada uno con tres repeticiones. 'Promedios con letras distintas ( $a, b, c$, etc.) en la misma columna, son significativamente diferentes (Tukey, 0.05). nd = no se hizo análisis de detección.

los productos hortofrutícolas frescos. Además, los desinfectantes solamente previenen la contaminación superficial, pero no tienen acceso al interior del tejido vegetal ni a las células endófitas de patógenos como Salmonella (Solomon et al., 2002).

\section{Respuesta del tejido de nopal a Salmonella}

En cortes longitudinales de cladodios in planta y de cladodios cortados de nopal verdura, realizados durante $7 \mathrm{~d}$ cada $24 \mathrm{~h}$, se observaron cambios de color y aspecto del tejido, los cuales se registraron como lesiones (daños) solamente en el sitio de inoculación con $S$. Typhimurium. En contraste, no se registró desarrollo de lesión en cladodios in planta ni en cladodios cortados donde solo se aplicó APA $0.1 \%$ sin la bacteria. Los cambios de color de tejido fueron de verde a café (oscurecimiento), y deshidratación del tejido. El inicio de las lesiones se registró a partir de las 24 h ddi; sin embargo, hubo diferencias entre cladodios en el desarrollo de las lesiones después de la inoculación (Cuadro 2).

En tejido de cladodio madre in planta la lesión se registró con oscurecimiento tenue y ningún otro daño. En cladodio secundario in planta la lesión se registró con oscurecimiento denso a las $48 \mathrm{~h}$ ddi, oscurecimiento tenue a 72 h ddi y deshidratación a las 96 h; ningún otro cambio se registró en las siguientes horas. En contraste, en cladodio secundario cortado la lesión se encontró a las 48 h ddi con oscurecimiento tenue, seguida de oscurecimiento denso a las $72 \mathrm{~h}$ ddi, y de apariencia deshidratada a las $144 \mathrm{~h}$. En este último caso se encontró que las lesiones se desprendían fácilmente del tejido sano. Los resultados obtenidos muestran que el porcentaje de daño se incrementó con el tiempo en los tejidos de cladodios inoculados. En los cladodios madre in planta y en los cortados la correlación fue de 0.98 y 0.99 ( $\mathrm{P} \leq 0.0002)$; en los cladodios secundarios in planta, la correlación fue de $0.77(\mathrm{P}=0.042)($ Cuadro 2).

Aunque Salmonella se ha considerado un patógeno de humanos que puede contaminar cladodios de nopal verdura (Hernández-Anguiano et al., 2009), aquí se demuestra su habilidad para inducir una respuesta de defensa en cladodios in planta y de enfermedad (oscurecimiento denso) en cladodios cortados. En el primer caso podría tratarse de una respuesta de hipersensibilidad por los síntomas característicos de rápido oscurecimiento durante las primeras 48 h, y deshidratación de tejido a las 96 h en los cladodios secundarios in planta. En el tejido oscurecido se aíslan microorganismos que acceden a las sustancias nutritivas de la planta, y sustancias con actividad antimicrobiana como compuestos fenólicos. 


\begin{tabular}{l}
$\begin{array}{l}\text { Cuadro 2. Correlación de Pearson entre el tiempo transcurrido después de la inoculación y el daño registrado } \\
\text { en cladodios de nopal. }\end{array}$ \\
\cline { 2 - 4 } Tiempo (h)
\end{tabular}

Al respecto, Gómez-Flores et al. (2006) encontraron algunos compuestos extraídos de plantas de Nopalea cochenillifera, aparentemente de naturaleza fenólica, que presentaron actividad antimicrobiana contra $S$. Typhimurium. La rápida disminución en la población bacteriana registrada en los cladodios secundarios in planta, se asoció con el pronto oscurecimiento del tejido infiltrado. En contraste, en cladodios secundarios cortados se detectó recuperación del nivel de la población bacteriana, después de un descenso temporal (Cuadro 1), lo cual permite inferir que la respuesta en los cladodios secundarios in planta está relacionada con la síntesis temprana o la acumulación de compuestos con actividad antimicrobiana, los cuales estarían ausentes o reducidos en los cladodios cortados.

Schikora et al. (2008) descubrieron que aunque $S$. Typhimurium puede activar el sistema inmune de las plantas, la bacteria puede vencer este sistema al activar la transcripción de genes relacionados con la virulencia, e invadir, proliferar y dispersarse para ocasionar síntomas de clorosis y marchitez en el tejido de plantas de Arabidopsis thaliana. De igual forma, Shirron y Yaron (2011) reportaron en plantas de tabaco (Nicotiana tabacum) que $S$. Typhimurium indujo una rápida respuesta de tipo hipersensible, la cual se asoció con la producción de especies reactivas de oxígeno (ROS, por sus siglas en inglés); la intensidad de esta respuesta fue menor que en plantas inoculadas con la bacteria fitopatógena Pseudomonas syringae.

En nopal la supervivencia de $S$. Typhimurium se asoció principalmente con la condición fisiológica de los cladodios; in planta el crecimiento de la bacteria se suprimió rápidamente y pocas o ninguna célula viable se recuperó a los $14 \mathrm{~d}$, mientras que en los cladodios cortados la bacteria pudo sobrevivir y multiplicarse. Según Saénz et al. (2006), una vez cosechados los productos hortofrutícolas entran en un rápido proceso de senescencia y se tornan más susceptibles a la invasión por microrganismos.

Por otra parte, las plantas pueden no "reconocer" a los patógenos de humanos como Salmonella y E. coli como potencialmente peligrosos para ellas y consecuentemente no iniciar respuesta de defensa (Berger et al., 2010). Pero estas bacterias no solo pueden inducir una respuesta de defensa en la planta sino que también tienen capacidad para suprimirla (Iniguez et al., 2005; Schikora et al., 2008; Shirron y Yaron, 2011), lo que indica la complejidad de estas interacciones. Por ello, la información del presente estudio contribuye al entendimiento de la interacción entre patógenos de humanos y plantas, fenómeno que aún no se conoce bien, así como de la función de las plantas en el ciclo de vida de bacterias enteropatógenas, como lo señalaron Barak y Schroeder (2012).

\section{CONCLUSIONES}

Salmonella Typhimurium presentó capacidad para persistir en suelo y tejido de nopal hasta por $14 \mathrm{~d}$. La capacidad de la bacteria para persistir en el tejido dependió del tipo y la condición fisiológica del cladodio. Esta bacteria también mostró capacidad de inducir una respuesta de defensa en cladodios in planta y enfermedad en los cortados.

\section{AGRADECIMIENTOS}

Al Consejo Nacional de Ciencia y Tecnología y al Colegio de Postgraduados, por la beca número 160232 otorgada a la primera autora durante sus estudios de doctorado. 


\section{BIBLIOGRAFÍA}

Barak J B, L Gorski, P Naraghi-Arani, A O Charkowski (2005) Salmonella enterica virulence genes are required for bacterial attachment to plant tissue. Appl. Environ. Microbiol. 71:5685-5691.

Barak J D, B K Schroeder (2012) Interrelationships of food safety and plant pathology: the life cycle of human pathogens on plants. Ann. Rev. Phytopath. 50:241-266.

Berger C N, S V Sodha, R K Shaw, P M Griffin, D Pink, P Hand, G Frankel (2010) Fresh fruit and vegetables as vehicles for the transmission of human pathogens. Environ. Microbiol. $12: 2385-2397$

Brandl M, R Amudson (2008) Leaf age as a risk factor in contamination of lettuce with Escherichia coli O157:H7 and Salmonella enterica. Appl. Environ. Microbiol. 74:2298-2306.

Doyle M P, M C Erickson (2008) Summer meeting 2007, the problems with fresh produce an overview. J. Appl. Microbiol. 105:317330 .

Franz E, A AVisser, A D Van Diepeningen, M M Klerks, A J Termorchuizen, A H C van Bruggen (2007) Quantification of contamination of lettuce by GFP-expressing Escherichia coli O157:H7 and Salmonella enterica serovar Typhimurium. Food Microbiol. 24:106-112.

Gómez-Flores R, P Tamez-Guerra, R Tamez-Guerra, C Rodríguez-Padilla, E Monreal-Cuevas, L A Hauad-Marroquín, C Córdova-Puente, A Rangel-Llanas (2006) In Vitro antibacterial and antifungal activities of Nopalea cochenillifera pad extracts. Am. J. Infect. Dis. 2:1-8.

Guan T Y, R A Holley (2003) Pathogen survival in swine manure environments and transmission of human enteric illness: a review. J. Environ. Qual. 32:383-392.

Guo X, J Chen, L R Beuchat, E R Brackett (2000) PCR detection of Salmonella enterica serotype Montevideo in and on raw tomatoes using primers derived from hilA. Appl. Environ. Microbiol. 66:5248-5252.

Guo X, J Chen, R E Brackett, L R Beuchat (2001) Survival of Salmonellae on and in tomato plants from the time of inoculation at flowering and early stages of fruit development through fruit ripening. Appl. Environ. Microbiol. 67:4760-4761.

Guo X, M W van Iersel, J Chen, R E Brackett, L R Beuchat (2002) Evidence of association of Salmonella with tomato plants grown hydroponically in inoculated nutrient solution. Appl. Environ. Microbiol. 68:3639-3643.

Hernández-Anguiano A M, P Landa-Salgado, G Mora-Aguilera, C A Eslava-Campos, J E Call, A C S Porto Fett, J B Luchansky (2009) Characterization of Salmonella spp. from nopal leaves and associated soil and water samples in Morelos, Mexico. Abstr..Annual Meet. Internat. Assoc. Food Protect. (P1-37):74-75.

Holden N, L Pritchard, I Toth (2009) Colonization outwith the colon: plants as an alternative environmental reservoir for human pathogenic enterobacteria. FEMS. Microbiol. Rev. 33:689-703.

Iniguez A L, Y Dong, H D Carter, B M M Ahmer, J M Stone, E W Tripplet (2005) Regulation of enteric endophytic bacterial colonization by plants defenses. Mol. Plant-Microbe Interact. 18:169-178

Islam M, J Morgan, M P Doyle, S C Phatak, P Millner, X Jiang (2004) Persistence of Salmonella enterica serovar Typhimurium on lettuce and parsley and in soils on which they were grown in fields treated with contaminated manure compost or irrigation water. Foodborne Path. Dis. 1:27-35.

Klerks M M, E Franz, M van Gent-Pelzer, C Zijlstra, A H C van Bruggen (2007a) Differential interaction of Salmonella enterica serovars with lettuce cultivars and plant-microbe factors influencing the colonization efficiency. ISME J. 1:620-631.

Klerks M M, M van Gent-Pelzer, E Franz, X Zijlstra, A H C van Bruggen (2007b) Physiological and molecular response of Lactuca sativa to colonization by Salmonella enterica serovar Dublin. Appl. Environ. Microbiol. 73:4905-4914.
Landa-Salgado P, A M Hernández-Anguiano, J Corrales-García, G Mora-Aguilera, C Chaidez-Quiroz (2009) Sobrevivencia de Salmonella Typhimurium en melón "Cantaloupe" durante el almacenamiento refrigerado en atmósferas controladas. Rev. Fitotec. Mex. 32:209-215.

Madigan M T, J M Martinko, J Parker (2001) Brock, Biología de los Microorganismos. 8a. ed. Prentice Hall. 986 p.

Natving E E, S C Ingham, B H Ingham, L R Cooperband, T R Roper (2002) Salmonella enterica serovar Typhimurium and Esch erichia coli contamination of root and leaf vegetables grown in soils with incorporated bovine manure. Appl. Environ. Microbiol. 68:2737-2744.

Norma Mexicana, NMX-AA-102-SCFI-2006 (2006) Calidad del aguadetección y enumeración de organismos coliformes, organismos coliformes termotolerantes y Escherichia coli presuntivamétodo de filtración en membrana. Publicada en el Diario Oficial de la Federacion del 21 de agosto de 2006.

Norma Oficial Mexicana, NOM-114-SSA1-1994, Bienes y servicios (1994) Método para la determinación de Salmonella en alimentos. Publicada en el Diario Oficial de la Federación del 22 de septiembre de 1995.

Pu S, J C Beaulieu, W Prinyawiwatkul, B Ge (2009) Effects of plant maturity and growth media bacterial and internalization of Escherichia coli O157:H7 in growing spinach leaves. J. Food Protect. 72:2313-2320.

Rahn K, S A de Grandis, R C Clarke, S A Mcewen, J E Galan, C Ginchio, R Curtis, C L Gyles (1992) Amplification of an invA gene sequence of Salmonella Typhimurium by polymerase chain reaction as a specific method of detection of Salmonella. Mol. Cell. Probes 6:271-279.

Saénz C, H Berger, J Corrales-García, L Galletti, V García del Cortázar, I Higuera, C Mondragón, A Rodríguez-Félix, E Sepúlveda, M A Varnero (2006) Utilización agroindustrial del nopal. Boletín de Servicios Agrícolas de la FAO. 169 p.

Santo Domingo J W, S Harmon, J Bennet (2000) Survival of Salmonella species in river water. Curr. Microbiol. 40:409-417.

Saucedo-Tamayo M del S, N Bañuelos-Flores, R M Cabrera P, N Ballesteros V (2006) La práctica de la medicina alternativa una realidad en el paciente diabético en Hermosillo, Sonora, México. Rev. Salud Púb. Nutr. 7:1-12.

Schikora A, A Carreri, E Charpentier, H Hirt (2008) The dark side of the salad: Salmonella Typhimurium overcomes the innate immune response of Arabidopsis thaliana and shows and endopathogenic lifestyle. PLoS One 3: e2279.doi:10.137/journal. pone.0002279.

Schikora A, A V García, H Hirt (2012) Plants as alternative hosts for Salmonella. Trends Plant Sci. 17:245-249.

Shirron B, S Yaron (2011) Active suppression of early immune response in tobacco by the human pathogen Salmonella Typhimurium. PLoS One 6: e18855.doi:10.1371/journal.pone.0018855.

Solomon E, Y Sima, K R Matthews (2002) Transmission of Escherichia coli $\mathrm{O} 157: \mathrm{H} 7$ from contaminated manure and irrigation water to lettuce plant tissue and its subsequent internalization. Appl. Environ. Microbiol. 68:397-400.

Stintzing F C, R Carle (2005) Cactus stems (Opuntia spp.): A review on their chemistry, technology, and uses. Mol. Nutr. Food Res. 49:175-194.

Warriner K, S Spaniolas, M Dickinson, C Wright, W Waites (2003) Internalization of bioluminescent Escherichia coli and Salmonella Montevideo in growing bean sprouts. J. Appl. Microbiol. 95:719-727.

Vidovic S, H C Block, D R Korber (2007) Effect of soil composition, temperature, indigenous microflora and environmental conditions on the survival of Escherichia coli O157:H7. Can. J. Microbiol. 57:822-829.

Zibilske L M, R W Weaver (1978) Effect of environmental factors on survival of Salmonella Typhimurium in soil. J. Environ. Qual. 7:593-597. 